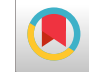

\title{
Prevalence and Related Factors to Herbal Medicines Use among Pregnant Females
}

\author{
Fatemeh Abdollahi ${ }^{1}$, Soghra Khani ${ }^{2}$ and Jamshid Yazdani Charati ${ }^{3,{ }^{*}}$ \\ ${ }^{1}$ Department of Public Health, Faculty of Health, Health Sciences Research Center, Addiction institute, Mazandaran University of Medical Sciences, Sari, Iran \\ ${ }^{2}$ Department of Midwifery, Faculty of Nasibeh Nursing and Midwifery, Mazandaran University of Medical Sciences, Sari, Iran \\ ${ }^{3}$ Department of Biostatistics, Faculty of Health, Traditional and Complementary Medicine Research Center, Addiction Institute, Mazandaran University of Medical Science, \\ Sari, Iran \\ "Corresponding author: Department of Biostatistics, Faculty of Health, Mazandaran University of Medical Sciences, P.O. Box: 481751665, KM 18 Farah Abab Rd., Payambar Aazam \\ Campus, Sari, Iran. Tel: +98-1113343082-5, Fax: +98-1513542473, Email: jamshid.charati@gmail.com
}

Received 2017 June 19; Accepted 2017 October 24.

\begin{abstract}
Background: Using herbal medicines during pregnancy has increased during the past decades.

Objectives: This study aimed at determining the prevalence and pattern of herbal medicines use during pregnancy in females.

Methods: In a cross-sectional study, 400 females admitted to Mazandaran hospitals postnatal ward were recruited during the first few days of postnatal period from March to June 2015 and completed a self-report socio-demographic questionnaire, including herbal medicines use extent, dosage, administration route, reasons for use, its effects, herbs administration timing, and whether use was reported to health care providers.

Results: Using herbal medicines by the respondents increased from $22.7 \%$ before pregnancy to $48.4 \%$ during pregnancy. The use of herbal medicines was significantly higher among females living in their own house and married to highly educated husbands, who were working as jobholders. Sour orange (30.76\%) and peppermint (22\%) were the most commonly reported herbs applied in most cases throughout pregnancy (45.36\%). The majority of females took one spoon of the herb per day (52.4\%) as brew (51.45\%), without the health providers' supervision (49.2\%). The most common reasons for using the herbs were to promote fetal health and intelligence (28.3\%). The majority of the users reported the effectiveness (96.4\%) of the herbs without any side effects (98.1\%).

Conclusions: Using herbal medicines that were chosen based on cultural beliefs during pregnancy was prevalent. The majority of females reported that herbs were effective without any side effects. The most common information sources used by the females were informal, and lacked knowledge about the herbs safety during pregnancy. Health care providers should inquire about herbs that women take during pregnancy.
\end{abstract}

Keywords: Herbal Medicines, Pregnancy, Prevalence

\section{Background}

The use of herbal medicines has increased during the recent decades (1). Historically, for centuries, herbal products have been taken as food or medicine in different patient groups as well as in the general population, in order to promote health $(2,3)$. Published documents estimated that herbal medicine use during pregnancy ranges from $1 \%$ to $87 \%$, worldwide (4). It is broadly prevalent among pregnant females in Iran (22.2\% and 67\%), with Anchusa officinalis, peppermint and frankincense being the most frequently used (3, 5-7).

It is strongly assumed that since herbal medicines are natural, they are safe (8). While herbal medicine chemicals have potential danger in case of being consumed incorrectly and interacting with other pharmaceuticals, they can trigger abnormal pathology due to toxicity $(8,9)$. Using herbal medicines during pregnancy is a significant concern because many are specifically taken for symptoms appearing during pregnancy, such as nausea and vomiting, and also have potential harm for fetal safety $(10,11)$. According to some studies, herbal medicines, such as Licorice (12) and St. John's wort $(13,14)$, have some adverse effects during pregnancy and post-partum period, including preterm labor, damage to oocytes and iron absorption inhibition, while other study results are in contrast $(15,16)$.

Since herbal medicines are extensively produced (8000 species) in Iran and in the provinces (2000 species), and considering their increased use among the population $(3,5-7,17,18)$, their potential interactions with other natural and chemical products and their side effects, specifically on the fetus during pregnancy, the present 
study aimed at determining the extent of herbal medicines used during pregnancy, the use prevalence and pattern and whether females taking them disclose use to health care providers.

\section{Objectives}

This study was performed as similar studies have been limited to certain geographical areas and also based on the capacity of the Mazandaran province in producing various species of herbal medicines.

\section{Methods}

In a cross-sectional study design, the prevalence and pattern of herbal medicines use during pregnancy was investigated from March to July 2015. A sample size of 400 was estimated using the formula for cross-sectional descriptive study with input $\mathrm{P}=0.51, \mathrm{z}=1.96, \alpha=0.05$, and $\mathrm{d}=$ 0.05 (3). Four cities, namely, Galogah, Behshahr, Neka, and Sari in the western and central part of the province were selected as the study locations.

During the first few postnatal days, the females were recruited via the convenience sampling method from governmental and non-governmental hospitals. All females delivering their babies alive during the study period were invited to take part in the study. The exclusion criteria were having a still birth or ill neonate, being sick during the study period, and lack of competence to provide informed consent.

The self-report validated questionnaires $(3,18)$ were distributed among the eligible females by midwives. The questionnaires included demographic and obstetrics data and also detailed information about herbal use from the last menstrual period (LMP) through the end of pregnancy. The socio-demographic and obstetric variables included age, education, and occupation of the females and their husbands, family income, residency, housing, parity, delivery type, gestational age at the time of delivery, the female's weight and height during the first trimester of pregnancy in order to calculate body mass index (BMI), and also the daily use of medications or supplements. The questionnaire's content validity was evaluated by five CAM, biostatistics, pharmacology, and public health specialists. The questionnaires on herbal medicines were implemented after pre-testing a sample of 40 post-partum females (Cronbach's alpha, 0.89).

In the present study, herbal medicines were defined as "products containing a plant, plant part, or plant extract with medicinal or preventive properties". To reduce the recall bias, 20 specific and more popular herbs reported in previous studies were recorded in the questionnaire (3, 5-7, 17,18 ) (Table 1). An open-ended question was also posed to identify the herbal medicines used during pregnancy for treating medical conditions or preserving health. In addition, the reasons for herbal medicines' use, the administration dosage (gram, tablet) and timing, frequency, administration route, effectiveness, side effects, and whether the females disclosed herbal use to their health care providers were asked.

IBM-SPSS software version 20 was used for data analysis. Descriptive statistics were applied to describe the characteristics and pattern of herbal medicines' use during pregnancy in the study sample. The results are presented in the form of proportions. The most prevalent herbal medicines were identified. Chi-square test was used to analyze categorical variables and frequency and percentages for herbal medicines' use during pregnancy was presented for each level of socio-demographic and obstetrics categorical variables. All tests with $\mathrm{P}<0.05$ were considered statistically significant. Mazandaran University of Medical Sciences ethics committee approved the study. A written consent was obtained from females after they were assured that their data would be kept confidential.

\section{Results}

In total, 400 females agreed to participate in this study. One sample was excluded from the analysis because of not completing the questionnaires. The mean age of the females was 28.00 (5.20) years with a range of 15 to 41 years. The education of about half of the females and their husbands was below diploma (53.9\% and $47.5 \%$, respectively), and their mean household income was 755852.53 \pm 392694.08 Tomans per month (equal 215.95 USD). Most of the females had medical insurance (90.80\%).

The majority of the participants came from urban areas (60.3\%), were housewives (92.3\%), had self-employed husbands (76.3\%), lived in nuclear families (87.1\%), and rental homes (54.7\%). About half of them (45.3\%) were primipara and their newborn infant was male (50.3\%). Most of the females delivered via cesarean section (71.5\%).

Approximately one-fifth (22.7\%) and a half (48.4\%) of the females used at least one type of herbal medicine before and during pregnancy, respectively. One-fifth (26.8\%) of the females took conventional medications during pregnancy and a minority of them (9.4\%) used it with herbal medicines, concurrently $(\mathrm{P}<0.05)$.

The herbal medicines' use during pregnancy was more common in females taking more herbs before pregnancy, living in their own house, and married to highly educated husbands working as state employees. Table 2 illustrates the characteristics of the users and non-users of herbal 


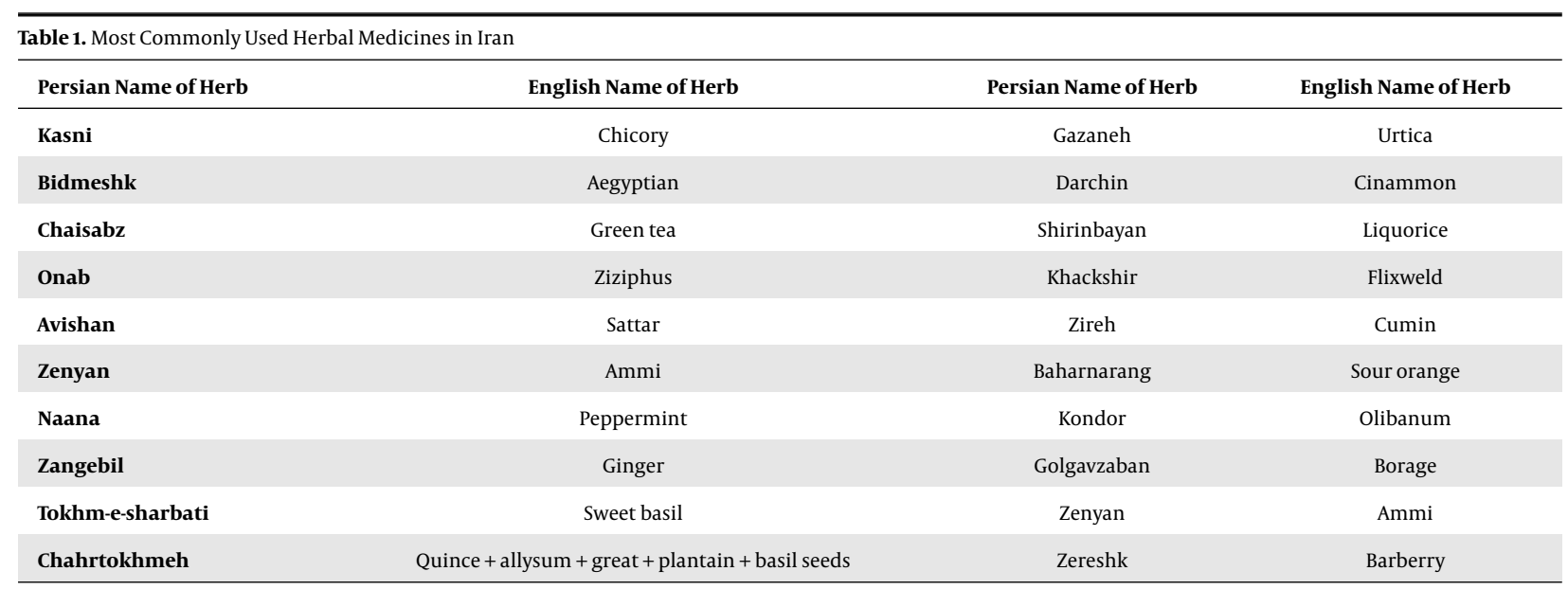

\begin{tabular}{lc}
\hline \multicolumn{2}{l}{ Table 3. Administration Time of Herbal Medicines During Pregnancy } \\
\hline Gestational Period & No. (\%) \\
\hline 1th trimester & $22(11.34)$ \\
\hline 2ed trimester & $12(6.18)$ \\
\hline 3rd trimester & $53(27.31)$ \\
\hline Throughout pregnancy & $88(45.36)$ \\
\hline During labor & $3(1.54)$ \\
\hline At time of sickness & $16(8.24)$ \\
\hline Total & $194(49.36)$ \\
\hline
\end{tabular}

medicines during pregnancy. Pearson P values for Chisquare test are also displayed.

The majority of women had taken at least one kind of herbal medicine throughout their pregnancy (45.36\%), while a small proportion of them (1.54\%) used herbs during labor. Table 3 reported that the administration time of herbal medicines' use was during pregnancy.

Among the users $(n=117)$, the most common herbal medicines were sour orange (30.76\%), peppermint (22.22\%), borage $(18.80 \%)$, flaxseed (14.52\%), and others (13.10). Approximately $70.94 \%$ of females $(n=83)$ used more than one herb during pregnancy.

More than half (51.45\%) of the herbs were taken in the form of brew, $36.40 \%$ as solution, $27.66 \%$ as extract, $7.76 \%$ as boiled, $4.36 \%$ as powder, and $0.97 \%$ as other forms. The majority of the users had taken one serving spoon of herb per day (52.4\%) and the frequency was $17.64 \%$ weekly, $14.7 \%$ monthly, $6.41 \%$ occasionally, and 5.84\% rarely.

Herbal medicines were used by women for a variety of reasons. The most common reasons were to promote fetal health and intelligence (28.3\%), to boost women's health status (27.4\%), to relieve common discomfort during pregnancy $(25.5 \%)$, and to restore youth (3.1\%).

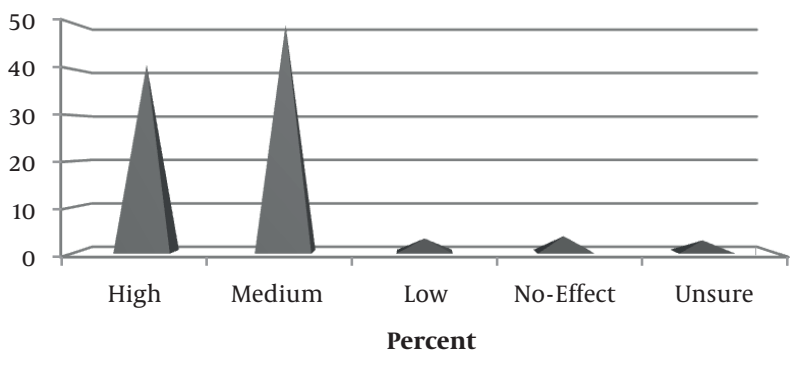

Figure 1. The women perception of the applied herbs' efficacy during pregnancy

Almost all users (96.4\%) perceived herbal medicines' effectiveness. Figure 1 illustrates the women's perception of the applied herbs' efficacy. In $41.2 \%$ of users, the women were fully satisfied with the herbs.

Out of 154 respondents, three (1.9\%) of the users reported some form of side effects after herbal medicines' administration, including vomiting $0.6 \%(n=2)$, weight loss $0.6 \%(n=2)$, and fever $0.3 \%(n=3)$. About half of the women reported that health providers supervised their herbal medicine' use during pregnancy (49.2\%).

The use of herbal medicines was advised to the majority of women by their mothers (26.3\%) followed by their relatives $(21.4 \%)$, mass media (11\%), health practitioners (10.4\%), friends (9.1\%), local herbs sellers (5.8\%), and others $7.8 \%$.

\section{Discussion}

In the present study, the prevalence and pattern of herbal medicines use and most frequently consumed herbs during pregnancy was investigated. High prevalence rate of herbal medicine use by pregnant women was 
consistent with previous reports from different regions of the country, reported to range from $22.2 \%$ in Tabriz (5) to $79.6 \%$ in Tehran $(6,7)$. The widespread popularity of the herbal medicines' use was also observed among pregnant females around the world, including $5.8 \%$ to $9.4 \%$ in the USA (11, 19), 69\% in Russia (20), 34.3\% in Malaysia (21), and $67.5 \%$ in Nigeria (22) as developed and developing countries. The global prevalence of herbal medicines' use during pregnancy continues to rise although, little scientific evidences behind their safety are available $(8,11,19)$.

Variability in the prevalence of herbal medicines' use may be related to the characteristics of the study population, cultural variations across the countries and regions, acces to herbal medicines, and use of different methods in various studies (design and time of the sampling, sample size, sampling methods, the method of data collection, and inclusion criteria). For example, in a self-reported data collection method, the response rate may decline (6).

Considering the socio-demographic characteristics, a statistically significant difference was observed between the herbs 'users and non-users in terms of housing, occupation, and education of the women' husbands. The use of herbs was higher in the pregnant women living in their own house with highly educated and state employee husbands. Some studies reported that women with high socioeconomic status could better afford to buy herbs (23).

The most common herbs used in the current study were sour orange, peppermint, and borage. Peppermint is the most commonly used herb reported in previous studies in Iran and in the Middle East (6, 7, 24). Ginger, anise, and thyme are the most commonly consumed herbs among the women from China, Ethiopia, Palestine, and Kazeron of Iran $(18,20,23,25)$. The most common herbs used in Australia, Norway, and Tuscany were Raspberry, Echinacea and St. John's wort (26-28). It seems that women chose the herbs, according to their culture and based on the seasons in different regions and countries. The present study was conducted in spring when it is time of harvesting sour orange in the north of Iran.

A considerable proportion of the population took herbs to promote fetal health. Herbal medicines may be applied to treat a variety of conditions. The health problems leading to its use vary geographically and from region to region $(2,11,18,20,29,30)$. They're primarily used for conditions related to pregnancy, such as nausea, preparation for labor, and fetal health rather than to treat chronic diseases $(11,18,20)$. In Iran, sour orange and peppermint are used for enhancing the beauty of the fetus and gastrointestinal problems, respectively (18).

In most studies, the proportion of herbal usage was the highest during the first trimester compared with the subsequent two trimesters $(3,11,18,20)$. Inconsistent with pre- vious reports, the women in this study used herbs throughout their trimesters. The time using herbs during pregnancy varied and depended on the reasons related to the herbs' use. Ginger was taken for nausea and vomiting in the first trimester (11,25), peppermint, thyme, chamomile, and green tea for bloating, stomach ache, and the maintenance of health throughout the trimesters $(6,11,31)$ and evening primrose oil for facilitating the labor in the end of pregnancy (32).

Similar to the current research, a Malaysian study found that the majority of women took one spoon of herbs daily in the form of brew (21). The inappropriateness of dosage and dosage form may be due to diverse cultural beliefs and practices in different nations. The safety of a herb could depend on dosage, the use frequency and administration form (33). This issue needs to be considered in the future.

Compatible with a study from Malaysia and Nigeria, most females in the present study considered herbs effective without any side effects $(21,22)$. Some problems not requiring treatment during pregnancy may be alleviated with herbal medicines (27). While most of the women strongly considered taking herbal medicines safe during pregnancy $(6,21,22,27)$, there is limited documentation about the efficacy and safety of most of these herbs during pregnancy $(8,24)$. Studies have reported some side effects of herbal medicines, including miscarriages and preterm labor (for example, chamomile, licorice, and deliberate) (33-35).

Similar to other studies' reports, herbal medicine users in the current study did not report use to their health care providers $(6,36)$. The pregnant females may think that health care providers generally disagree with using herbs during pregnancy, as a result, they did not disclose this matter to them (27).

This study had some limitations, including the selfreport retrospective data collection among the women with healthy infants, which may have resulted in underestimation of the prevalence of herbal medicines' use during pregnancy.

\subsection{Conclusions}

Herbal medicines' use was prevalent among this study's participants. The majority of the users took herbs in appropriate amounts and on a daily basis without any side effects throughout the trimesters. Because of the pharmacological component in non-licensed herbal preparations and the possibility of potential harm to both mothers and the fetus, especially in the organogenesis period (the first trimester of pregnancy), it is necessary to evaluate risks and safety of herbal medicines during pregnancy. Health care providers should be familiar with pop- 
ular herbal medicines' use in their region, ask women if they are taking any herbs during pregnancy, and teach them about the possible interaction between herbs and conventional medicines and also the potential side effects.

\section{Acknowledgments}

Mazandaran University of Medical Sciences (MAZUMS) is sincerely appreciated for their financial support (grant No.: 1208) granted to midwives to help the data collection and also the authors appreciate the participation of the women involved in this study.

\section{Footnotes}

Authors' Contribution: Study concept and design and drafting of the manuscript: Fatemeh Abdollahi; purification, analysis and interpretation of data, and acquisition of data: Fatemeh Abdollahi, Jamshid Yazdani Cherati and Soghra Khani. All authors read and approved the final manuscript.

Conflict of Interests: No competing interests have been declared.

\section{References}

1. Barnes PM, Powell-Griner E, McFann K, Nahin RL. Complementary and alternative medicine use among adults: United States, 2002. Adv Data. 2004;(343):1-19. [PubMed: 15188733].

2. Nordeng H, Bayne K, Havnen GC, Paulsen BS. Use of herbal drugs during pregnancy among 600 Norwegian women in relation to concurrent use of conventional drugs and pregnancy outcome. Complement Ther Clin Pract. 2011;17(3):147-51. doi: 10.1016/j.ctcp.2010.09.002. [PubMed: 21742280].

3. Sereshti M, Azari P, Rafieian-Kopaei M, Kheiri S. [Use of herbal medicines by pregnant women in Shahr-e-Kord]. J Reproduction Infini. 2006;7(2). Persian.

4. Adams J, Lui CW, Sibbritt D, Broom A, Wardle J, Homer C, et al. Women's use of complementary and alternative medicine during pregnancy: a critical review of the literature. Birth. 2009;36(3):237-45. doi:10.1111/j.1523-536X.2009.00328.x. [PubMed:19747271].

5. Sattari M, Dilmaghanizadeh M, Hamishehkar H, Mashayekhi SO. Selfreported Use and Attitudes Regarding Herbal Medicine Safety During Pregnancy in Iran. Jundishapur J Nat Pharm Prod. 2012;7(2):45-9. [PubMed: 24624153]. [PubMed Central: PMC3941856].

6. Hashem Dabaghian F, Abdollahi Fard M, Shojaei A, Kianbakht S, Zafarghandi N, Goushegir A. Use and attitude on herbal medicine in a group of pregnant women in Tehran.J Med Plant. 2012;1(41):22-33.

7. Raoufi-Nejad K, Javadi M, Torkamandi H, Rajabi M, Moeini A, Khanavi $\mathrm{M}$, et al. Adverse drug reactions of herbal medicines during pregnancy amongst Iranian women. Res Pharm Sci. 2012;7(5):980.

8. Tiran D. The use of herbs by pregnant and childbearing women: a riskbenefit assessment. Complement Ther Nurs Midwifery. 2003;9(4):176-81. doi:10.1016/S1353-6117(03)00045-3. [PubMed: 14556766].

9. Dugoua JJ, Mills E, Perri D, Koren G. Safety and efficacy of ginkgo (Ginkgo biloba) during pregnancy and lactation. Can J Clin Pharmacol. 2006;13(3):e277-84. [PubMed: 17085776].
10. Vutyavanich T, Kraisarin T, Ruangsri R. Ginger for nausea and vomiting in pregnancy: randomized, double-masked, placebo-controlled trial. Obstet Gynecol. 2001;97(4):577-82. [PubMed: 11275030].

11. Broussard CS, Louik C, Honein MA, Mitchell AA, National Birth Defects Prevention S. Herbal use before and during pregnancy. Am J Obstet Gynecol. 2010;202(5):443 e1-6. doi: 10.1016/j.ajog.2009.10.865. [PubMed: 20035911].

12. Veale DJ, Oliver DW, Havlik I. The effects of herbal oxytocics on the isolated "stripped" myometrium model. Life Sci. 2000;67(11):1381-8. [PubMed: 10972206].

13. Greeson JM, Sanford B, Monti DA. St. John's wort (Hypericum perforatum): a review of the current pharmacological, toxicological, and clinical literature. Psychopharmacology (Berl). 2001;153(4):402-14. [PubMed: 11243487].

14. Dugoua JJ, Mills E, Perri D, Koren G. Safety and efficacy of St. John's wort (hypericum) during pregnancy and lactation. Can J Clin Pharmacol.2006;13(3):e268-76. [PubMed: 17085775].

15. Klier CM, Schafer MR, Schmid-Siegel B, Lenz G, Mannel M. St. John's wort (Hypericum perforatum) is it safe during breastfeeding? Pharmacopsychiatry. 2002;35(1):29-30. doi: 10.1055/s-2002-19832. [PubMed: 11819157].

16. Smith C, Crowther C, Willson K, Hotham N, McMillian V. A randomized controlled trial of ginger to treat nausea and vomiting in pregnancy. Obstet Gynecol. 2004;103(4):639-45. doi: 10.1097/01.AOG.0000118307.19798.ec. [PubMed:15051552].

17. Sanagoh L, Joybari A, Khanjani A. . International congress on traditional and complementary medicine. Sari. 2008.

18. Tabatabaee M. Use of herbal medicine among pregnant women referring to Valiasr Hospital in Kazeroon, Fars, South of Iran. J Med Plant. 2011;1(37):96-108.

19. Louik C, Gardiner P, Kelley K, Mitchell AA. Use of herbal treatments in pregnancy. Am J Obstet Gynecol. 2010;202(5):439 e1-439 e10. doi: 10.1016/j.ajog.2010.01.055. [PubMed: 20452484]. [PubMed Central: PMC2867842].

20. Kennedy DA, Lupattelli A, Koren G, Nordeng H. Herbal medicine use in pregnancy: results of a multinational study. BMC Complement Altern Med. 2013;13:355. doi: 10.1186/1472-6882-13-355. [PubMed: 24330413]. [PubMed Central: PMC4029224].

21. Kim Sooi L, Lean Keng S. Herbal Medicines: Malaysian Women's Knowledge and Practice. Evid Based Complement Alternat Med. 2013;2013:438139. doi: 10.1155/2013/438139. [PubMed: 24093047]. [PubMed Central: PMC3777224].

22. Fakeye TO, Adisa R, Musa IE. Attitude and use of herbal medicines among pregnant women in Nigeria. BMC Complement Altern Med. 2009;9:53. doi: 10.1186/1472-6882-9-53. [PubMed: 20043858]. [PubMed Central: PMC2808296].

23. Al-Ramahi R, Jaradat N, Adawi D. Use of herbal medicines during pregnancy in a group of Palestinian women. J Ethnopharmacol. 2013;150(1):79-84. doi: 10.1016/j.jep.2013.07.041. [PubMed: 23933314].

24. John LJ, Shantakumari N. Herbal Medicines Use During Pregnancy: A Review from the Middle East. Oman Med J. 2015;30(4):229-36. doi: 10.5001/omj.2015.48. [PubMed: 26366255]. [PubMed Central: PMC4561638].

25. Bayisa B, Tatiparthi R, Mulisa E. Use of herbal medicine among pregnant women on antenatal care at nekemte hospital, Western ethiopia. Jundishapur J Nat Pharm Prod. 2014;9(4). e17368. [PubMed: 25625049]. [PubMed Central: PMC4302397].

26. Forster DA, Denning A, Wills G, Bolger M, McCarthy E. Herbal medicine use during pregnancy in a group of Australian women. BMC Pregnancy Childbirth. 2006;6:21. doi: 10.1186/1471-2393-6-21. [PubMed: 16780602]. [PubMed Central: PMC1544352].

27. Nordeng H, Havnen GC. Impact of socio-demographic factors, knowledge and attitude on the use of herbal drugs in pregnancy. Acta Obstet Gynecol Scand.2005;84(1):26-33. doi:10.1111/j.0001-6349.2005.00648.x. [PubMed: 15603563]. 
28. Lapi F, Vannacci A, Moschini M, Cipollini F, Morsuillo M, Gallo E, et al. Use, Attitudes and Knowledge of Complementary and Alternative Drugs (CADs) Among Pregnant Women: a Preliminary Survey in Tuscany. Evid Based Complement Alternat Med. 2010;7(4):47786. doi: 10.1093/ecam/nen031. [PubMed: 18955336]. [PubMed Central: PMC2892351].

29. Kashani L, Hassanzadeh E, Mirzabeighi A, Akhondzadeh S. Knowledge, attitude and practice of herbal remedies in a group of infertile couples. Acta Med Iran. 2013;51(3):189-94. [PubMed: 23605605].

30. Holst L, Wright D, Haavik S, Nordeng H. Safety and efficacy of herbal remedies in obstetrics-review and clinical implications. Midwifery. 2011;27(1):80-6. doi: 10.1016/j.midw.2009.05.010. [PubMed: 19782445].

31. Sawalha AF. Consumption of prescription and non-prescription medications by pregnant women: A cross sectional study in Palestine. Islam Univ J. 2015;15(2).

32. Dove D, Johnson P. Oral evening primrose oil: its effect on length of pregnancy and selected intrapartum outcomes in low-risk nulliparous women. J Nurse Midwifery. 1999;44(3):320-4. [PubMed: 10380450].

33. Cuzzolin L, Francini-Pesenti F, Verlato G, Joppi M, Baldelli P, Benoni G. Use of herbal products among 392 Italian pregnant women: focus on pregnancy outcome. Pharmacoepidemiol Drug Saf. 2010;19(11):11518. doi: 10.1002/pds.2040. [PubMed: 20872924].

34. Johns T, Sibeko L. Pregnancy outcomes in women using herbal therapies. Birth Defects Res B Dev Reprod Toxicol. 2003;68(6):501-4. doi: 10.1002/bdrb.10052. [PubMed: 14745987].

35. Strandberg TE, Andersson S, Jarvenpaa AL, McKeigue PM. Preterm birth and licorice consumption during pregnancy. Am J Epidemiol. 2002;156(9):803-5. [PubMed:12396997].

36. Pinn G, Pallett L. Herbal medicine in pregnancy. Complement Ther Nurs Midwifery. 2002;8(2):77-80. doi: 10.1054/ctnm.2001.0620. [PubMed: 12188161]. 
Table 2. Characteristics of the Users and Non Users of Herbal Medicines During Pregnancy ${ }^{\mathrm{a}}$

\begin{tabular}{|c|c|c|c|c|}
\hline Women's Characteristics & Total $=399$ & Herbal Users = 155 & Herbal Non-Users $=165$ & P Value \\
\hline Age $(y)$ & & & & 0.48 \\
\hline Younger than 25 & $105(26.5)$ & $45(14.2)$ & $45(14.2)$ & \\
\hline $25-35$ & $163(41.2)$ & $65(20.4)$ & $62(19.5)$ & \\
\hline 36 or older & $128(32.3)$ & $44(13.8)$ & $55(17.9)$ & \\
\hline Lower secondary $(\leq 9)$ & $88(22.1)$ & $28(8.8)$ & $46(14.4)$ & \\
\hline Upper secondary (10 - 12) & $215(53.9)$ & $87(27.2)$ & $80(25)$ & \\
\hline Completed high school and higher $(\geq 12)$ & $96(24.1)$ & $40(12.5)$ & $39(12.2)$ & \\
\hline Husband's education $(y)$ & & & & 0.03 \\
\hline Lower secondary $(\leq 9)$ & $109(27.4)$ & $40(12.5)$ & $46(14.4)$ & \\
\hline Upper secondary (10 - 12) & $189(47.5)$ & $65(20.4)$ & $87(27.3)$ & \\
\hline Completed high school and higher $\geq 12$ ) & $100(25.1)$ & $49(15.4)$ & $32(10)$ & \\
\hline Employment & & & & 0.06 \\
\hline Housewife & $362(92.3)$ & $137(43.20$ & $152(47.9$ & \\
\hline Employed & $30(7.7)$ & $18(3.2)$ & $10(5.7)$ & \\
\hline Husband's employment & & & & 0.01 \\
\hline Job holder & $300(76.3)$ & $34(10.8)$ & $14(4.4)$ & \\
\hline Self-employed & $60(15.3)$ & $113(41.0)$ & $129(35.9)$ & \\
\hline Farmer & $23(5.9)$ & $5(3.8)$ & $12(1.6)$ & \\
\hline Other & $10(2.5)$ & $1(2.2)$ & $7(0.3)$ & \\
\hline Total household income (Tomans/month) & & & & 0.15 \\
\hline Medium $(700,000-1000,000)$ & $120(55.3)$ & $42(25.4)$ & $52(31.5)$ & \\
\hline High (more than 1000,000 ) & $24(11.1)$ & $9(5.5)$ & $9(5.5)$ & \\
\hline Family structure & & & & 0.08 \\
\hline Nuclear & $48(12.9)$ & $14(7.6)$ & $23(4.6)$ & \\
\hline Extended & $323(87.1)$ & $138(45.4)$ & $129(42.4)$ & \\
\hline Housing & & & & 0.01 \\
\hline Rental & $214(54.7)$ & $69(21.8)$ & $102(32.3)$ & \\
\hline House owner & $177(45.3)$ & $86(27.2)$ & $59(18.7)$ & \\
\hline Residency & & & & 0.42 \\
\hline Urban & $240(60.3)$ & $94(30.4)$ & $100(31.3)$ & \\
\hline Rural & $158(39.7)$ & $58(18.2)$ & $64(30.1)$ & \\
\hline BMI & $13(5.3)$ & & & 0.057 \\
\hline$\leq 19.7$ & $105(42.7)$ & $3(16)$ & $6(3.2)$ & \\
\hline $19.8-25.9$ & $71(28.9)$ & $22(11.7)$ & $55(29.3)$ & \\
\hline $26-29$ & $57(23.2)$ & $24(12.8)$ & $35(18.6)$ & \\
\hline$>29$ & & $23(12.4)$ & $20(10.6)$ & \\
\hline Children No. & $178(45.3)$ & & & 0.14 \\
\hline
\end{tabular}




\begin{tabular}{|c|c|c|c|c|}
\hline 1 & & $78(24.5)$ & $79(21.9)$ & \\
\hline 2 & $192(48.9)$ & $70(25.4)$ & $81(21.9)$ & \\
\hline 3 or more children & $13(5.9)$ & $7(4.1)$ & $13(2.4)$ & \\
\hline Gestational age at delivery time & & & & 0.19 \\
\hline$<37$ & $39(9.8)$ & $11(3.4)$ & $18(5.6)$ & \\
\hline$\geq 37$ & $360(90.2)$ & $144(40.5)$ & $147(45.9)$ & \\
\hline Delivery type & & & & 0.34 \\
\hline Vaginal & $110(28.5)$ & $48(15.5)$ & $45(14.5)$ & \\
\hline Cesarean section & 276 (71.5) & $105(33.9)$ & $112(36.1)$ & \\
\hline Baby's gender & & & & 0.36 \\
\hline Boy & $194(50.3)$ & $77(24.7)$ & $78(25)$ & \\
\hline Girl & $192(49.7)$ & $74(23.7)$ & $83(26.6)$ & \\
\hline Conventional drug use & & & & 0.03 \\
\hline No & $248(73.2)$ & $125(39.4)$ & $117(36.7)$ & \\
\hline Yes & $91(26.8)$ & $30(9.4)$ & $47(14.7)$ & \\
\hline Previous herbal medicines' use before pregnancy & & & & 0.001 \\
\hline No & $184(77.3)$ & $38(16.1)$ & $146(61.9)$ & \\
\hline Yes & $54(22.7)$ & $47(19.9)$ & $5(2.1)$ & \\
\hline
\end{tabular}

${ }^{\text {a }}$ Values are presented as No. (\%). 